\title{
Seven years' experience with etidronate in a woman with anorexia nervosa and vertebral fractures
}

This article was published in the following Dove Press journal:

Therapeutics and Clinical Risk Management

4 July 2011

Number of times this article has been viewed

\author{
Jun Iwamoto' \\ Yoshihiro Sato ${ }^{2}$ \\ Mitsuyoshi Uzawa ${ }^{3}$ \\ Tsuyoshi Takeda' \\ Hideo Matsumoto' \\ Institute for Integrated Sports \\ Medicine, Keio University School of \\ Medicine, Tokyo, Japan; ${ }^{2}$ Department \\ of Neurology, Mitate Hospital, \\ Fukuoka, Japan; ${ }^{3}$ Department \\ of Orthopaedic Surgery, Keiyu \\ Orthopaedic Hospital, Gunma, Japan
}

Correspondence: Jun Iwamoto Institute for Integrated Sports Medicine, Keio University School of Medicine, 35 Shinanomachi, Shinjuku-ku,

Tokyo 160-8582, Japan

$\mathrm{Tel}+8 \mid 33353$ |2 I।

Fax +8I 333529467

Email jiwamoto@a8.keio.jp

\begin{abstract}
We report the case of a 30-year-old Japanese woman with anorexia nervosa and vertebral fractures who was treated with etidronate. She had a history of anorexia nervosa, chronic back pain, osteoporosis, and multiple vertebral fractures (morphometric fractures) that responded poorly to treatment with alfacalcidol ( $1 \mu \mathrm{g}$ daily) for 1 year and was treated with cyclical etidronate ( $200 \mathrm{mg}$ for 2 weeks every 3 months) for 7 years. The lumbar spine bone mineral density (BMD) increased, and the serum alkaline phosphatase and urinary cross-linked $\mathrm{N}$-terminal telopeptides of type I collagen levels and back pain decreased. During the 7-year period of treatment with etidronate, no osteoporotic fractures occurred. The patient experienced neither renal dysfunction nor hyperparathyroidism caused by osteomalacia. No gastrointestinal tract symptoms were observed. Thus, etidronate was effective for increasing the lumbar spine BMD and reducing back pain over a 7-year period without causing either osteoporotic fractures or adverse events.
\end{abstract}

Keywords: anorexia nervosa, bulimia, etidronate, bone mineral density, osteoporosis, vertebral fracture

\section{Background}

Anorexia nervosa is an eating disorder characterized by refusal to maintain a healthy body weight and an obsessive fear of gaining weight. A Japanese epidemiological survey on anorexia nervosa in 1985 and 1992 revealed that the prevalence was 3.6-4.5 per 100,000 among the general population, 6.3-9.7 per 100,000 among the female population, and 25.2-30.7 per 100,000 among the 13-29 year-old female population. ${ }^{1}$ Another Japanese epidemiological survey on anorexia nervosa in a geographically defined area (Niigata Prefecture) in 1997 also showed that the estimated prevalence was 4.8 per 100,000 females and 17.1 for the age group of 15-29 years. ${ }^{2}$ The prevalence of anorexia nervosa in the Japanese population may be decreasing and appears to be lower than in European Caucasian populations.

Osteoporosis is a very prevalent complication of anorexia nervosa. It places patients at an increased lifetime risk for fractures. The loss of bone mineral density (BMD) can occur rapidly and very early during the course of anorexia nervosa. ${ }^{3}$ Early detection and weight restoration are of utmost importance. ${ }^{4}$ Although an improvement in BMD is possible after a substantial body mass increase in conjunction with a well-balanced, controlled diet, BMD loss may never recover completely, even once weight has been restored. ${ }^{3}$

The etiology of osteoporosis in patients with anorexia nervosa is multifactorial. In addition to reduced estrogen and progesterone levels, excess cortisol levels and 
low levels of insulin growth factor-1 (IGF-1) and leptin, a correlate for bone formation, are observed. ${ }^{3-6}$ Bone resorption is also considered to be of great importance for osteoporosis. ${ }^{7}$ Successful treatments to reverse BMD loss in patients with anorexia nervosa are lacking, ${ }^{3}$ and no good evidence to guide medicinal interventions is available. ${ }^{4}$ Antiresorptive agents such as bisphosphonates are one candidate for the treatment of osteoporosis in patients with anorexia nervosa.

Etidronate is a bisphosphonate that inhibits osteoclastmediated bone resorption. ${ }^{8}$ It has been used in the treatment of postmenopausal osteoporosis. A study in Japan showed that the percentage increase in the lumbar spine BMD after 1 year of etidronate treatment (200 mg daily for 2 weeks every 3 months) was $2.4 \%$ in patients with involutional osteoporosis. ${ }^{9}$ Systematic reviews have revealed that the relative risk ( $95 \%$ confidence interval) for developing vertebral fractures during treatment with etidronate $(400 \mathrm{mg}$ for 2 weeks every 12 weeks) as a secondary prevention is 0.53 ( 0.32 to 0.87$)$ in Western patients with postmenopausal osteoporosis. ${ }^{10}$ Thus, etidronate may be effective for increasing the lumbar spine BMD and preventing vertebral fractures in patients with high bone turnover and osteoporosis. However, very few reports have shown the long-term outcome of bisphosphonate treatment in young patients with anorexia nervosa and osteoporosis. We report the case of a young woman who had a history of anorexia nervosa, chronic back pain, osteoporosis, and multiple vertebral fractures (morphometric fractures) who was treated with cyclical etidronate for 7 years, showing changes in the lumbar spine BMD, bone turnover marker levels, and back pain.

\section{Case report}

\section{Characteristics of the case}

A premenopausal Japanese woman, 30 years of age, consulted our clinic because of spinal deformity (round back) and chronic back pain. Despite these subjective symptoms, which had continued for several years, she had never been examined or treated for them. She had a history of anorexia nervosa treated for 5 years in a psychiatry clinic before her first consultation with our clinic. She had lost $10 \mathrm{~kg}$ as a result of anorexia but had gained $20 \mathrm{~kg}$ as a result of bulimia nervosa after her psychiatric treatment. At the time of her consultation with our clinic, her height was $145 \mathrm{~cm}$, her body weight was $59 \mathrm{~kg}$, and her body mass index (BMI) was $28.1 \mathrm{~kg} / \mathrm{m}^{2}$. Treatment of anorexia nervosa appeared to be successful, and she had already recovered from the eating disorder. She did not have any disturbance in menstruation at the time of her consultation with our clinic. According to the Japanese criteria, ${ }^{11}$ she was considered obese $\left(\mathrm{BMI}>25 \mathrm{~kg} / \mathrm{m}^{2}\right)$. She had no past history of reflux esophagitis, gastric or duodenal ulcer, gastrectomy, or metabolic bone diseases and had never taken medicine that affected bone metabolism.

The level of chronic back pain was 5 , as evaluated quantitatively by assessing the mood of the patient according to the face scale score (scores are arranged in decreasing order of mood and numbered from 1-10, with 1 representing the most positive mood and 10 representing the most negative mood). ${ }^{12}$ She had stiffness and tenderness in her back muscles. However, she did not have any neurological deficits.

The radiographs of the thoracic and lumbar spine showed multiple vertebral fractures (morphometric fractures) in the thoracic and lumbar spine according to the Japanese diagnostic criteria for osteoporotic vertebral fractures ${ }^{13,14}$ and increased kyphosis of the thoracic spine (Figure 1). To understand the pathogenesis of bone fragility and to determine an effective treatment using medication, the lumbar spine BMD was measured and biochemical analyses were performed. Table 1 shows the baseline BMD and biochemical markers. The lumbar spine (L1-L4) BMD was $0.803 \mathrm{~g} / \mathrm{cm}^{2}$, corresponding to $77 \%$ of the young adult mean (YAM). The patient was diagnosed as having osteoporosis according to the Japanese criteria in women: ${ }^{13,14}$ patients whose BMD was $<70 \%$ of the YAM or $70 \%-80 \%$ of the YAM and who had a history of osteoporotic fractures are regarded as having osteoporosis. The serum calcium, phosphorus, alkaline phosphatase (ALP), and creatinine levels measured using standard laboratory techniques were within the normal ranges. The serum intact parathyroid hormone (PTH) level measured using a chemiluminescent immunoassay (CLIA) was within the normal range. The patient had no other abnormalities in their blood examinations. The active form of vitamin $\mathrm{D}_{3}$, vitamin $\mathrm{K}_{2}$, intramuscular elcatonin, and etidronate were available for the treatment of osteoporosis. Bone turnover markers, such as bone-specific ALP and cross-linked N-terminal telopeptides of type I collagen (NTX), were also not available.

\section{Outcome of I year of alfacalcidol treatment}

Alfacalcidol treatment ( $1 \mu \mathrm{g}$ daily) was started despite the lack of secondary hyperparathyroidism because this was the standard treatment for osteoporosis at that time. The lumbar spine BMD, serum calcium, phosphorus, ALP levels, and the face scale score (for back pain) were evaluated every 6 months. Radiographs of the thoracic and lumbar spine were also taken every year to identify new vertebral 


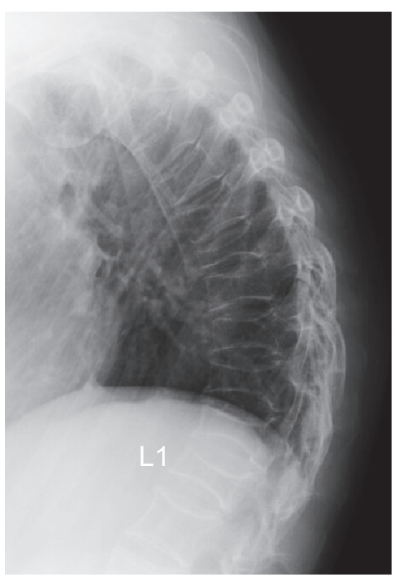

Thoracic spine

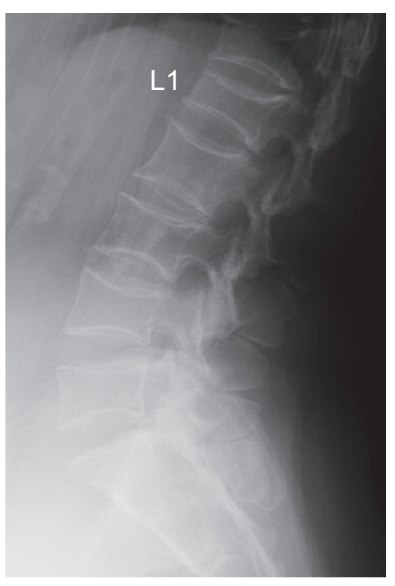

Lumbar spine
Figure I Radiographs of the thoracic and lumbar spine - lateral views before treatment. The radiographs of the thoracic and lumbar spine at her first consultation with our clinic showed multiple vertebral fractures (morphometric fractures) in the thoracic and lumbar spine and increased kyphosis of the thoracic spine.

fractures. After 1 year of alfacalcidol treatment, however, the lumbar spine BMD decreased (Figure 2) and the face scale score (back pain) did not improve, although no new vertebral fractures occurred. The serum ALP level did not change significantly during the 1-year period of alfacalcidol treatment (Figure 3). The serum calcium, phosphorus, and creatinine levels were within the normal ranges. Therefore, alternative treatments needed to be considered because the young female patient was anxious about the progression of kyphosis of the thoracic spine.

Table I Baseline BMD and biochemical markers

\begin{tabular}{lll}
\hline & & Normal range \\
\hline $\begin{array}{l}\text { Lumbar spine BMD }\left(\mathrm{g} / \mathrm{cm}^{2}\right) \\
\text { \% YAM in BMD }\end{array}$ & 0.803 & \\
Serum & 77 & \\
Calcium $(\mathrm{mg} / \mathrm{dL})$ & 9.5 & $8.4-10.2$ \\
Phosphorus $(\mathrm{mg} / \mathrm{dL})$ & 3.4 & $2.5-4.5$ \\
ALP $(\mathrm{IU} / \mathrm{L})$ & 320 & $100-340$ \\
Intact PTH $(\mathrm{pg} / \mathrm{mL})$ & 17 & $10-66$ \\
Total protein $(\mathrm{g} / \mathrm{dL})$ & 7.7 & $6.5-8.2$ \\
Albumin $(\mathrm{g} / \mathrm{dL})$ & 4.3 & $3.7-5.2$ \\
Asparate aminotransferase $(\mathrm{U} / \mathrm{L})$ & 19 & $11-35$ \\
Creatinine $(\mathrm{mg} / \mathrm{dL})$ & 0.52 & $0.47-0.79$ \\
Total cholesterol $(\mathrm{mg} / \mathrm{dL})$ & 206 & $130-219$ \\
HDL-cholesterol $(\mathrm{mg} / \mathrm{dL})$ & 48.2 & $40-90$ \\
LDL-cholesterol $(\mathrm{mg} / \mathrm{dL})$ & 135 & $70-139$ \\
Triglyceride $(\mathrm{mg} / \mathrm{dL})$ & 114 & $30-149$ \\
WBC $(\mathrm{I} / \mu \mathrm{L})$ & 5400 & $3500-9100$ \\
RBC $\left(\times 10^{4} / \mu \mathrm{L}\right)$ & 459 & $376-516$ \\
Hemoglobin $(\mathrm{g} / \mathrm{dL})$ & 13.2 & $11.2-15.2$ \\
Platelet $\left(\times 10^{4} / \mu \mathrm{L}\right)$ & 21.1 & $14.0-37.9$ \\
\hline
\end{tabular}

Abbreviations: BMD, bone mineral density; YAM, young adult mean; ALP, alkaline phosphatase; PTH, parathyroid hormone; HDL, high-density lipoprotein; LDL, lowdensity lipoprotein; WBC, white blood cell; RBC, red blood cell.

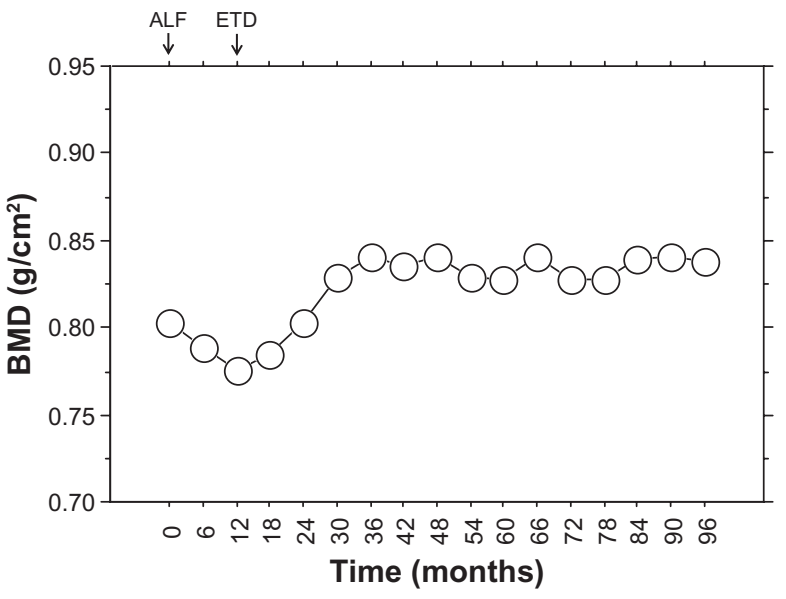

Figure 2 Changes in lumbar spine BMD. After I year of alfacalcidol treatment, the lumbar spine BMD decreased. Then, treatment was switched to cyclical etidronate and was sustained for 7 years. The lumbar spine BMD increased after the start of etidronate treatment. The increase rate was $3.6 \%$ at I year, $8.4 \%$ at 2 years, $8.4 \%$ at 3 years, $6.8 \%$ at 4 years, $6.7 \%$ at 5 years, $8.3 \%$ at 6 years, and $8.1 \%$ at 7 years.

Abbreviations: ALF, alfacalcidol; BMD, bone mineral density; ETD, etidronate.

\section{Outcome of 7 years of etidronate treatment}

The patient was evaluated again by measuring the lumbar spine BMD and the serum calcium, phosphorus, ALP, intact PTH, and urinary NTX levels (Table 2). Measurement of the urinary NTX level, a bone turnover marker, recently became available. The urinary NTX level measured using an enzymelinked immunosorbent assay (ELISA) was $88.4 \mathrm{nM} \mathrm{BCE/}$ $\mathrm{mM} \mathrm{Cr}$, suggesting high bone turnover osteoporosis (normal range: $35.3-54.3 \mathrm{nM} \mathrm{BCE} / \mathrm{mM} \mathrm{Cr}) .{ }^{15}$ The serum calcium, phosphorus, and ALP levels were within the normal ranges. The serum intact PTH level was also within the normal range, suggesting the absence of hyperparathyroidism. The face scale score (back pain) was 5. After informed consent was obtained from the patient, treatment was switched to the antiresorptive agent cyclical etidronate (200 $\mathrm{mg}$ daily for 2 weeks every 3 months) and was sustained for 7 years. Nitrogen-containing bisphosphonates like alendronate and risedronate or anabolic agents like teriparatide were not available at the time when etidronate treatment was started. The urinary NTX level was measured after 3 months of etidronate treatment. The lumbar spine BMD, serum calcium, phosphorus, ALP, creatinine levels, and the face scale score (for back pain) were evaluated every 6 months during the 7 -year period of etidronate treatment. Radiographs of the thoracic and lumbar spine were also taken every year to identify new vertebral fractures. In Japan, the measurement of the urinary NTX level is covered by health insurance only twice (at the start of medication and within 6 months after the start of medication). Because the measurement of the 

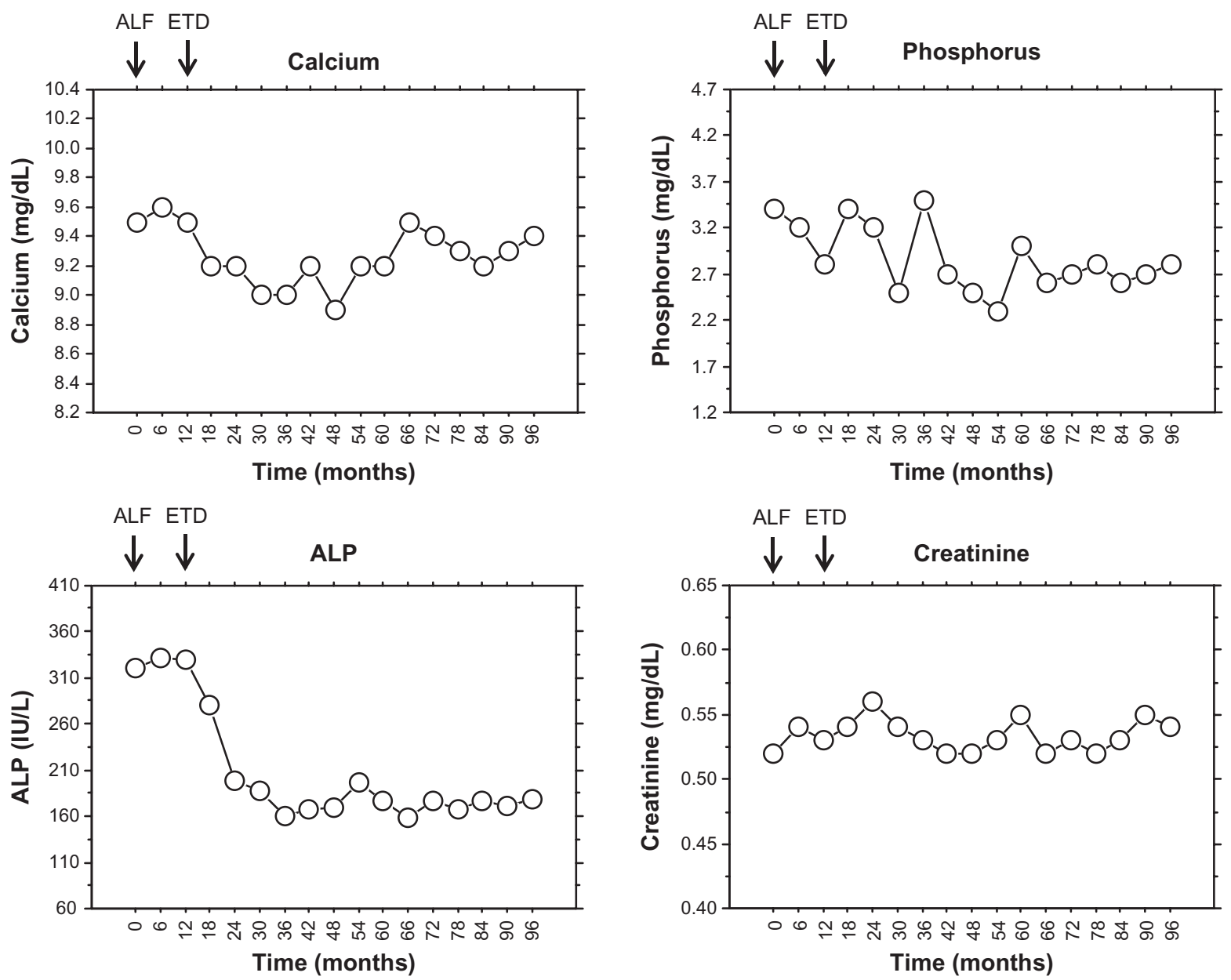

Figure 3 Changes in serum calcium, phosphorus, ALP, and creatinine. After I year of treatment with alfacalcidol, the serum ALP level did not change significantly. Then, treatment was switched to cyclical etidronate and was sustained for 7 years. The serum ALP markedly decreased. The rate of reduction in the serum ALP level was $40.0 \%$ at I year, $51.5 \%$ at 2 years, and $48.8 \%$ at 3 years. This reduction was sustained after 3 years ( $46.4 \%$ at 4 year, $46.7 \%$ at 5 years, $46.7 \%$ at 5 years, and $46.1 \%$ at 7 years). The serum calcium, phosphorus, and creatinine levels stayed within the normal ranges during the 7-year period of etidronate treatment.

Abbreviations: ALF, alfacalcidol; ALP, alkaline phosphatase; ETD, etidronate.

serum bone-specific ALP (bone formation marker) level is not covered by health insurance for the monitoring of osteoporosis treatment, we substituted the serum total ALP level as a bone formation marker.

Figure 2 shows the longitudinal changes in the lumbar spine BMD during the 7-year period of etidronate treatment. The lumbar spine BMD increased after the start of etidronate treatment. The increase rate was $3.6 \%$ at 1 year, $8.4 \%$ at 2 years, $8.4 \%$ at 3 years, $6.8 \%$ at 4 years, $6.7 \%$ at 5 years, $8.3 \%$ at 6 years, and $8.1 \%$ at 7 years. The urinary NTX level decreased to $45.2 \mathrm{nM} \mathrm{BCE} / \mathrm{mM} \mathrm{Cr}$ after 3 months of etidronate treatment. The reduction rate was $48.9 \%$. Figure 3 shows the longitudinal changes in the serum calcium, phosphorus, ALP, and creatinine levels during the 7-year period of etidronate treatment. The serum ALP markedly decreased. The rate of reduction in the serum ALP level was $40.0 \%$ at 1 year, $51.5 \%$ at 2 years, and $48.8 \%$ at 3 years. This reduction was sustained after 3 years $(46.4 \%$ at 4 years, $46.7 \%$ at 5 years, $46.7 \%$ at 5 years, and $46.1 \%$ at 7 years). The serum calcium, phosphorus, and creatinine levels stayed within the normal ranges during the 7-year period of etidronate treatment. After 7 years of etidronate treatment, the serum PTH level was $13 \mathrm{pg} / \mathrm{mL}$, which was within the normal range. The face scale score (for back pain) decreased to 3 after 6 months of etidronate treatment. At that time, the patient began walking for exercise (30 minutes of outdoor walking) 3-4 days a week for the treatment of obesity. This reduction in back pain was maintained after 6 months (face scale score was 2 or 3 thereafter). Her body weight decreased to $50 \mathrm{~kg}$ (BMI: $23.8 \mathrm{~kg} / \mathrm{m}^{2}$ ) after 1 year of exercise. After 7 years of treatment, her height was $144 \mathrm{~cm}$, her body weight was $46 \mathrm{~kg}$, and her BMI was $22.2 \mathrm{~kg} / \mathrm{m}^{2}$, indicating the absence of obesity. 
Table 2 BMD and biochemical markers after I-year alfacalcidol treatment

\begin{tabular}{lll}
\hline & & Normal range \\
\hline Lumbar spine BMD $\left(\mathrm{g} / \mathrm{cm}^{2}\right)$ & 0.775 & \\
\% YAM in BMD & 74 & \\
Serum & & \\
$\quad$ Calcium $(\mathrm{mg} / \mathrm{dL})$ & 9.5 & $8.4-10.2$ \\
$\quad$ Phosphorus $(\mathrm{mg} / \mathrm{dL})$ & 2.8 & $2.5-4.5$ \\
$\quad$ ALP $(\mathrm{IU} / \mathrm{L})$ & 330 & $100-340$ \\
Intact PTH $(\mathrm{pg} / \mathrm{mL})$ & 15 & $10-66$ \\
Urine & & \\
NTX (nM BCE/mM Cr) & 88.4 & $9.3-54.3$ \\
\hline
\end{tabular}

Abbreviations: BMD, bone mineral density; YAM, young adult mean; ALP, alkaline phosphatase; NTX, cross linked N-terminal telopeptides of type I collagen; BCE, bone collagen equivalent; $\mathrm{Cr}$, creatinine.

After 7 years of etidronate treatment, radiographs of the thoracic and lumbar spine revealed no evidence of new thoracic or lumbar vertebral fractures (Figure 4). During the 7-year period of etidronate treatment, nonvertebral osteoporotic fractures did not occur in the hip, wrist, or shoulder.

No adverse gastrointestinal symptoms were observed. As shown by the serum creatinine and intact PTH levels, the patient experienced neither renal dysfunction nor secondary hyperparathyroidism as a result of osteomalacia.

\section{Discussion}

We report the case of a young woman who had a history of anorexia nervosa, chronic back pain, osteoporosis, and multiple vertebral fractures (morphometric fractures) treated with cyclical etidronate for 7 years. BMD loss in patients with anorexia nervosa is thought to never recover completely,

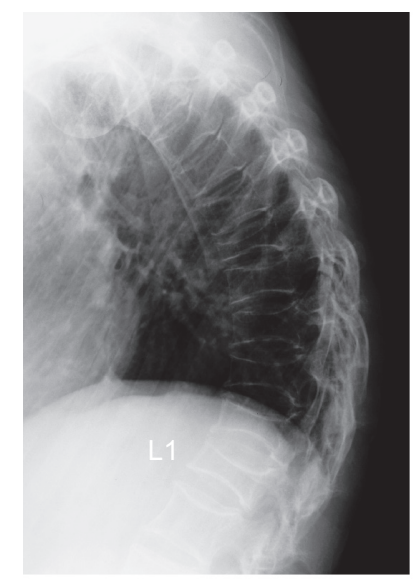

Thoracic spine

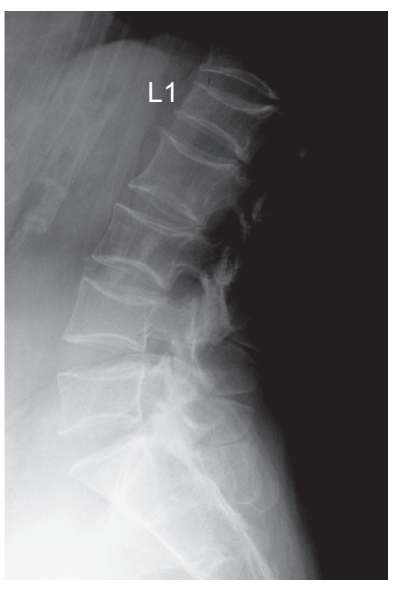

Lumbar spine
Figure 4 Radiographs of the thoracic and lumbar spine - lateral views after treatment. The radiographs of the thoracic and lumbar spine after I year of treatment with alfacalcidol and 7-year treatment with etidronate showed no new incident vertebral fractures. even once the body weight has been restored. ${ }^{1}$ Although body weight was gained as a result of bulimia after psychiatric treatment, the current patient had osteoporosis and multiple vertebral fractures. However, successful treatments to reverse BMD loss in patients with anorexia nervosa are lacking. ${ }^{1}$ The discussion points are 1) whether etidronate treatment is suitable for young women with multiple vertebral fractures, 2) the long-term efficacy and safety of etidronate treatment, 3) the mechanism for the pain relief effect of etidronate treatment, and 4) how long etidronate treatment should be continued.

The contraindications for etidronate treatment are severe renal dysfunction, osteomalacia, pregnancy, and childhood. The current patient had neither renal dysfunction nor secondary hyperparathyroidism caused by osteomalacia. The patient was a young woman (30 years old) but was not pregnant. The safety of bisphosphonate treatment during human pregnancy has not been well established. However, Ornoy et al ${ }^{16}$ reported that no major congenital abnormalities were found in the offspring of 24 women who were treated with alendronate before or at the beginning of pregnancy. Levy et a ${ }^{17}$ suggest that preconceptional and first-trimester use of bisphosphonates may not pose substantial fetal risks. Vujasinovic-Stupar et $\mathrm{al}^{18}$ reported that sequential treatment with etidronate and pamidronate increased the lumbar spine BMD and reduced back pain in a young woman with pregnancy-associated spinal osteoporosis but did not cause any neonatal adverse effects. They implied that although the prepregnancy use of bisphosphonates does not pose a substantial fetal risk, their use in women of childbearing age may best be done only when strong clinical indications exist. Etidronate will be liberated by the skeleton only when the bone in which the drug is deposited is destroyed; its half-life in the body is dependent on the rate of bone turnover and may be in excess of 1 year. ${ }^{19}$ Etidronate was considered to be acceptable in young patients with multiple fractures in terms of the treatment of severe osteoporosis, who did not have the possibility of a future pregnancy in several years. The current patient was able to understand the possible influence of etidronate on the fetal skeleton.

Alfacalcidol was often used for the treatment of osteoporosis before etidronate became available. A study showed that alfacalcidol treatment ( $1 \mu \mathrm{g}$ daily) and calcium supplementation sustained the lumbar spine BMD $(0.65 \%$ increase from the baseline) in Japanese postmenopausal women with osteoporosis. ${ }^{20}$ However, because the current patient was thought to have responded poorly to 1 year of alfacalcidol treatment, her medication was switched to etidronate. We were not able to evaluate serum 25-hydroxyvitamin D. However, based on 
the low serum PTH level, the patient was suggested not to have hypovitaminosis D or secondary hyperparathyroidism. A few reports have shown the long-term efficacy of etidronate treatment in patients with osteoporosis. Sato et $\mathrm{al}^{21}$ reported that long-term ( 7 years) cyclical etidronate treatment ( $200 \mathrm{mg} /$ day for 2 weeks every 3 months) and alfacalcidol ( $0.75 \mu \mathrm{g}$ daily) plus calcium supplementation were safe and effective for the prevention and treatment of glucocorticoidinduced osteoporosis in Japanese patients with connective tissue diseases (age: 21-73 years). The increase in the lumbar spine BMD at the end of 7 years was $6.7 \%$ in the subgroup of premenopausal women. ${ }^{21}$ Miller et $\mathrm{al}^{22}$ also reported the efficacy and safety of long-term ( 7 years) cyclical etidronate treatment (400 mg/day for 2 weeks every 12 weeks) and calcium supplementation in postmenopausal Western women with osteoporosis. The increase in the lumbar spine BMD at the end of 7 years was $7.6 \%$, and the incidence of vertebral fractures was reduced after 7 years of etidronate treatment. ${ }^{22}$ These reports suggest that long-term cyclical etidronate is a safe and effective treatment for osteoporosis. The current case report confirmed the long-term efficacy and safety of etidronate treatment, and the increase in the lumbar spine BMD after 7 years of etidronate treatment was $8.1 \%$, consistent with the results of previous studies. ${ }^{21,22}$

After her back pain decreased following 6 months of etidronate treatment, the patient began walking for exercise (30 minutes of outdoor walking) 3-4 days a week for the treatment of obesity. Available evidence suggests that aerobics, weight-bearing, and resistance exercises are all effective in increasing the BMD of the lumbar spine and that walking is effective on the hips in postmenopausal women. ${ }^{23}$ However, although high-intensity progressive resistance training is efficacious in increasing the BMD of the lumbar spine in premenopausal women, the effect of walking exercise on the BMD remains to be established in young women. ${ }^{23}$ Consequently, it remains uncertain whether there was an additive effect of etidronate and walking exercise on the lumbar spine BMD in the current patient.

Etidronate decreased back pain. However, the mechanism responsible for the pain relief effect of bisphosphonates remains uncertain. One possible mechanism may involve bone resorption, because the efficacy of bisphosphonates for bone pain in patients with avascular necrosis of the hip, osteoporotic vertebral fractures, skeletal metastases, or Paget's disease of the bone has been demonstrated. ${ }^{24-28}$ Other possibilities may involve neuropeptides that are active during pain transmission, such as substance $\mathrm{P}$ and calcitonin gene-related peptide (CGRP), and inflammatory cytokines, such as tumor necrosis factor- $\alpha$ (TNF- $\alpha) .{ }^{29-32}$ Bisphosphonates may suppress the production of substance P, CGRP, and TNF- $\alpha,{ }^{33,34}$ possibly reducing back pain.

How long patients with osteoporosis can continue to receive bisphosphonate treatment remains to be established. The prolonged suppression of remodeling is associated with the accumulation of microdamage, advanced glycation products, and an increased tissue mineral density, while stopping treatment results in the reemergence of remodeling. ${ }^{35}$ Seeman inferred that stopping antiresorptive treatment was more likely to do net harm than continuing the treatment. ${ }^{35}$ Thus, antiresorptive treatment should be continued as long as possible in patients at risk of fractures. The current patient continued etidronate treatment for 7 years. Neither osteoporotic fractures nor adverse events occurred during this time. The patient is continuing etidronate treatment and is being carefully followed-up by physicians.

The clinical risk factors of fractures in Japan include current smoking, maternal history of hip fractures, alcohol consumption ( $>2$ units daily), age ( $>75$ years), leanness (body mass index $<18.5 \mathrm{~kg} / \mathrm{m}^{2}$ ), and history of steroid use. ${ }^{36}$ Thus, weight loss due to anorexia nervosa can partly contribute to occurrence of osteoporosis. Vertebral fractures related to osteoporosis are more common in Japanese elderly than in Caucasian elderly. ${ }^{37}$ The incidence of vertebral fractures in the $50 \mathrm{~s}, 60 \mathrm{~s}, 70 \mathrm{~s}$, and $80 \mathrm{~s}$ is reported to be 5.2, 12.4, 24.5, and 56.1 per 1000 person-years, respectively in Japanese women without a vertebral fracture and 36.2, 59.7, 88.0, and 141.0 per 1000 person-years, respectively in Japanese women with a prior vertebral fracture. ${ }^{37}$ Thus, the incidence of vertebral fracture increases approximately exponentially with age after 50 years. ${ }^{37}$ Although vertebral fractures are not common in Japanese women $<50$ years of age, osteoporosis is a very prevalent complication in young women with anorexia nervosa. Thus, the strategy for preventing osteoporotic fractures in young women with a history of anorexia nervosa needs to be established. This case report may be intriguing, especially because it raises additional questions that could stimulate further research.

In conclusion, we report the case of a young woman with a history of anorexia, chronic back pain, osteoporosis, and multiple vertebral fractures (morphometric fractures) who was treated with cyclical etidronate for 7 years. Etidronate was effective in increasing the lumbar spine BMD and reducing back pain without causing either osteoporotic fractures or adverse events. However, further careful observation is needed to confirm the safety of etidronate in young women with osteoporosis and possibly fetuses. 


\section{Disclosure}

No conflicts of interest were declared in relation to this paper.

\section{References}

1. Kuboki T, Nomura S, Ide M, et al. Epidemiological data on anorexia nervosa in Japan. Psychiatry Res. 1996;62:11-16.

2. Nakamura K, Yamamoto M, Yamazaki O, et al. Prevalence of anorexia nervosa and bulimia nervosa in a geographically defined area in Japan. Int J Eat Disord. 2000;28:173-180.

3. Mehler PS, Cleary BS, Gaudiani JL. Osteoporosis in anorexia nervosa. Eat Disord. 2011;19:194-202.

4. Mehler PS, MacKenzie TD. Treatment of osteopenia and osteoporosis in anorexia nervosa: a systematic review of the literature. Int $J$ Eat Disord. 2009;42:195-201.

5. Legroux-Gérot I, Vignau J, Biver E, et al. Anorexia nervosa, osteoporosis and circulating leptin: the missing link. Osteoporos Int. 2010;21:1715-1722.

6. Wolfert A, Mehler PS. Osteoporosis: prevention and treatment in anorexia nervosa. Eat Weight Disord. 2002;7:72-81.

7. Horst-Sikorska W, Ignaszak-Szczepaniak M. The role of anorexia nervosa in secondary osteoporosis development with the risk for low energy fractures. Endokrynol Pol. 2011;62:45-47.

8. Rogers MJ, Frith JC, Luckman SP, et al. Molecular mechanism of action of bisphosphonate. Bone. 1999;24(5 Suppl):73S-79S.

9. Fujita T, Orimo H, Inoue T, et al. Clinical effect of bisphosphonate and vitamin $\mathrm{D}$ on osteoporosis: reappraisal of a multicenter double-blind clinical trial comparing etidronate and alfacalcidol. $J$ Bone Miner Metab. 2007;2:130-137.

10. Wells GA, Cranney A, Peterson J, et al. Etidronate for the primary and secondary prevention of osteoporotic fractures in postmenopausal women. Cochrane Database Syst Rev. 2008;23(1):CD003376.

11. Chin R, Miyazaki S. Criteria of obesity and obesity disease in Japan. Nippon Rinsho. 2009;67:297-300. [In Japanese]

12. Lorish CD, Maisiak R. The face scale: a brief, nonverbal method for assessing patient mood. Arthritis Rheum. 1986;29:906-909.

13. Orimo H, Sugioka Y, Fukunaga M, et al. Diagnostic criteria of primary osteoporosis. J Bone Miner Metab. 1998;16:139-150.

14. Orimo H, Hayashi Y, Fukunaga M, et al. Diagnostic criteria for primary osteoporosis: year 2000 revision. J Bone Miner Metab. 2001;19:331-337.

15. Nishizawa Y, Nakamura T, Ohta H, et al; Committee on the Guidelines for the Use of Biochemical Markers of Bone Turnover in Osteoporosis Japan Osteoporosis Society. Guidelines for the use of biochemical markers of bone turnover in osteoporosis (2004). J Bone Miner Metab. 2005;23:97-104.

16. Ornoy A, Wajnberg R, Diav-Citrin O. The outcome of pregnancy following pre-pregnancy or early pregnancy alendronate treatment. Reprod Toxicol. 2006;22:578-579.

17. Levy S, Fayez I, Taguchi N, et al. Pregnancy outcome following in utero exposure to bisphosphonates. Bone. 2009;44:428-430.

18. Vujasinovic-Stupar N, Pejnovic N, Markovic L, et al. Pregnancyassociated spinal osteoporosis treated with bisphosphonates: long-term follow-up of maternal and infants outcome. Rheumatol Int. February 16, 2011. [Epub ahead of print]

Therapeutics and Clinical Risk Management

\section{Publish your work in this journal}

Therapeutics and Clinical Risk Management is an international, peerreviewed journal of clinical therapeutics and risk management, focusing on concise rapid reporting of clinical studies in all therapeutic areas, outcomes, safety, and programs for the effective, safe, and sustained use of medicines. This journal is indexed on PubMed Central, CAS,
19. Dunn CJ, Fitton A, Sorkin EM. Etidronate acid: a review of its pharmacological properties and therapeutic efficacy in resorptive bone disease. Drugs Aging. 1994;5:446-474.

20. Orimo H, Shiraki M, Hayashi Y, et al. Effects of $1 \alpha$-hydroxyvitamin $\mathrm{D}_{3}$ on lumbar bone mineral density and vertebral fractures in patients with osteoporosis. Calcif Tissue Int. 1994;54:370-376.

21. Sato S, Takada T, Katsuki Y, et al. Long-term effect of intermittent cyclical etidronate therapy on corticosteroid-induced osteoporosis in Japanese patients with connective tissue disease: 7-year followup. $J$ Rheumatol. 2008;35:142-146.

22. Miller PD, Watts NB, Licata AA, et al. Cyclical etidronate in the treatment of postmenopausal osteoporosis: efficacy and safety after seven years of treatment. Am J Med. 1997;103:468-476.

23. Iwamoto J, Sato Y, Takeda T, Matsumoto H. Role of sport and exercise in the maintenance of female bone health. $J$ Bone Miner Metab. 2009;27:530-537.

24. Agarwala S, Sule A, Pai BU, et al. Alendronate in the treatment of avascular necrosis of the hip. Rheumatology (Oxford). 2002;41:346-347.

25. Gangji V, Appelboom T. Analgesic effect of intravenous pamidronate on chronic back pain due to osteoporotic vertebral fractures. Clin Rheumatol. 1999;18:266-267.

26. Glover D, Lipton A, Keller A, et al. Intravenous pamidronate disodium treatment of bone metastases in patients with breast cancer. A doseseeking study. Cancer. 1994;74:2949-2955.

27. Hortobagyi GN, Terhiault RL, Porter L, et al. Efficacy of pamidronate in reducing skeletal complications in patients with breast cancer and lytic bone metastases. $N$ Engl J Med. 1996;335:1785-1791.

28. Siris ES, Chines AA, Altman RD, et al. Risedronate in the treatment of Paget's disease of bone: an open label, multicenter study. $J$ Bone Miner Res. 1998;13:1032-1038.

29. Brown MF, Hukkanen MV, McCarthy ID, et al. Sensory and sympathetic innervation of the vertebral endplate in patients with degenerative disc disease. J Bone Joint Surg Br. 1997;79:147-153.

30. Hartman JM, Berger A, Baker K, et al; POWER. (Premenopausal, Osteoporosis, Women, Alendronate, Depression) Study Group. Quality of life and pain in premenopausal women with major depressive disorder: the POWER Study. Health Qual Life Outcomes. 2006;4:2.

31. Ohtori S, Inoue G, Koshi T, et al. Sensory innervation of lumbar vertebral bodies in rats. Spine (Phila Pa 1976). 2007;32:1498-1502.

32. Ohtori S, Inoue G, Koshi T, et al. Characteristics of sensory dorsal root ganglia neurons innervating the lumbar vertebral body in rats. $J$ Pain. 2007;8:483-488.

33. Bianchi M, Franchi S, Ferrario P, et al. Effects of the bisphosphonate ibandronate on hyperalgesia, substance $\mathrm{P}$, and cytokine levels in a rat model of persistent inflammatory pain. Eur J Pain. 2008; 12:284-292.

34. Orita S, Ohtori S, Koshi T, et al. The effects of risedronate and exercise on osteoporotic lumbar rat vertebrae and their sensory innervation. Spine. 2010;35:1974-1982.

35. Seeman E. To stop or not to stop, that is the question. Osteoporos Int. 2009;20:187-195.

36. Orimo H. Japanese guideline for prevention and treatment of osteoporosis. Life Science. 2006. [In Japanese]

37. Fujiwara S, Kasagi F, Masunari N, et al. Fracture prediction from bone mineral density in Japanese men and women. J Bone Miner Res. 2003;18:1547-1553.
EMBase, Scopus and the Elsevier Bibliographic databases. The manuscript management system is completely online and includes a very quick and fair peer-review system, which is all easy to use. Visit http://www.dovepress.com/testimonials.php to read real quotes from published authors. 